\title{
An analysis of gaps in performance among development stages of integration in SCM
}

\author{
Heesung Bae*
}

\begin{abstract}
This research empirically analyzes gaps in performance among development stages of integration in supply chain management (SCM). The used variables are integration such as internal and external and performance such as cost and service. The population is international freight forwarders in the Republic of Korea and the sample frame is the membership list of the Korean International Freight Forwarders Association. The used methodology in this research is various: Cronbach's alpha, factor analysis, cluster analysis, analysis of variance and post hoc analysis. It is important to ascertain the position in which they are included and the position is concerned with internal integration and external integration because the aim of this research is to ascertain where the forwarders are in development stages of integration. According to prior research, development stages of integration are regarded as the flow from internal to external. However, this research suggests that development stages of integration do not explain the flow of the stages but explain the strategic choice concerned with their current decision-making.
\end{abstract}

Keywords: Forwarders, Development stages, Integration, Performance, SCM

JEL classification numbers: L80, M10

Submission Date: 24/08/2012 Revision Date: 17/11/2012

* Ph.D. candidate, Business School, University of Hull, UK

Email: sunnybh@lyocs.co.kr 


\section{INTRODUCTION}

A supply chain has at least three or more components: supplier, manufacturer, customer, logistics service provider, and others. These participants conduct cooperative activities with a common objective. Supply chain participants should have a general view of the entire supply chain. The most important aim of SCM is to overcome an internal-only viewpoint and adopt a perspective that focuses on an entire supply chain. In addition, companies that have effective SCM also focus on performances indicators, such as high profits, resource-sharing and cost-saving (Holmberg, 2000). The focus on supply chains has changed the essential view of firms beyond an interface only between suppliers and customers toward integration.

Effective SCM should result in the integration of all activities into a process, and conversely, it should not cause interruptions in logistical processes. It should include all departments in a firm and connect external partners in the supply chain, such as suppliers, customers, logistical service providers and information system providers (Bae, 2011; Barratt, 2004; Mason et al., 2007; Matopoulos et al., 2007). The character of SCM is that all processes should be evident as an integrated system. As a result, supply chain participants can efficiently operate their systems by removing overlaps and inefficiencies in inter- and intra-organizational activities. The above purpose demonstrates the necessity of SCM.

Prior research on SCM has mostly investigated manufacturing firms (Gunasekaran et al., 2004; Lau et al., 2010; Min et al., 2005; Simatupang and Sridharan, 2005; So and Sun, 2010). In particular, Korean firms buy raw materials from overseas, manufacture products and sell the products overseas. Moreover, they manufacture goods in low cost countries and sell the goods overseas or import goods from these manufacturing countries into the Republic of Korea. Under these circumstances, the importance of global SCM is not to be overlooked. International freight forwarders also fulfill the work of international logistics brokers to act on behalf of manufacturing firms. Therefore, they provide manufacturing firms with international logistics services such as global SCM.

Integration can be considered through two viewpoints: structural and behavioral. The former concerns vertical and horizontal integration (Barrett, 2004; Mason et al., 2007), and the latter concerns the width and depth of integration (Min et al., 2005). According to prior research, integration can be classified into internal and external, and it is developed in sequence: internal integration, external integration and then supply chain integration (Barratt, 2004; Narasimhan and Kim, 2001; Stank et al., 2001/2002). However, firms choose their strategy on the basis of the circumstances that they face. For this reason, they might choose a strategy such as internal integration or external 
integration on the basis of their environmental recognition. This viewpoint comes from strategic fit by Venkatraman (1989). According to Frohlich and Westbrook (2001), there are different viewpoints of integration between manufacturing firms and other industrial service firms. Therefore, the present research will investigate gaps in performance among the development stages of integration considering the strategy of international freight forwarders. The contributions of this study are as follows. This research can suggest development stages of integration from the viewpoint of a strategic choice of international freight forwarders. In addition, the results of this research can influence the strategic choice of chief executive officers, which may be manifest in superior performance.

Research on the relationships between international freight forwarders and their partners has rarely been conducted; research from the viewpoint of the service providers in international logistics is also lacking. According to prior research, trends in logistics research have focused on the internal aspects of a firm (Mollenkopf et al., 2000; Williams et al., 1997). In addition, this research on the relationships between firms in logistics research has approached a viewpoint of SCM (Bae et al., 2012; Bagchi et al., 2005; Gimenez, 2006; Wiengarten et al., 2010; Wu, 2006). Therefore, the objectives of this study are as follows: first, to ascertain where firms are in the development stages and, second, to verify the gaps in performance among the development stages of integration in SCM.

\section{LITERATURE REVIEW}

There are four aims of the literature review: the first is to ascertain inter-organizational networks, the second is to explain the literature review regarding supply chain integration, and the third is to account for the development stages of integration in SCM.

\subsection{Inter-organizational networks}

Methods of logistics management are developed in three consecutive stages: efficiency of separate logistical functions, integrated efficiency of intra-firm logistics and overall efficiency between supply chain partners (Barratt, 2004; Sheu et al., 2006; Simatupang and Soidharan, 2005). Manufacturing firms should focus on logistical efficiency in the entire process but they should also concentrate on their core competence. For this reason, leading firms have been outsourcing logistics to external experts such as international freight forwarders rather than maintaining an internal 
provider.

International freight forwarders should provide shippers with efficient international logistics services through close cooperation with their business partners. Regarding inter-organizational networks, their activities can be explained as "make-or-buy decisions" with two aspects. First, resources can be acquired through the mechanism of a market or hierarchically organized firms following vertical integration (O'Donnell et al., 2001). "Buy" can dominate the mechanism of a market when firms purchase resources. An essential prerequisite of "buy" is that a market is stable and that there is no transaction-specific cost (Williamson, 1991). However, when a transaction is uncertain and firms are required to pay a transaction-specific cost in a market, firms that are organized hierarchically could appear in the market. These firms perform manufacturing and marketing processes in their organized hierarchy and internalize the functions of the market; therefore, this aspect can be explained as "make". In this situation, firms avoid the transaction-specific cost and inefficient market systems. However, there are neutral positions, such as joint ventures, long-term subsidiary contracts and alliances and these aspects can be explained as an inter-organizational network. The network can explain the relationships between international freight forwarders and their partners. The reason is that these relationships are not vertically integrated as a transaction in a market but rather as an alliance between partners. Therefore, alliance-oriented firms should have collaborative climates with their partners. Firms should be operated as inter-organizational networks (Williamson, 1996) in addition to "make-or-buy decisions". In addition, when firms are organized in networks, they can achieve performance via the relationships of the network in which they are included.

These inter-organizational networks can be classified as follows: vertical network and horizontal network (Mason et al., 2007). The former is composed of all participants in a supply chain, from raw material suppliers to final customers. The relationships in the network adjust to a flow of inter-complementary resources. Conversely, the latter includes cooperative firms such as logistics service providers and information system providers as well as practical and potential competitors in the case of joint logistics (Elg and Johansson, 1996). Therefore, a focus on the network aims at the relationships of the participants.

Second, a basic assumption of networks is that a firm depends on resources that are under the control of other firms. The acquisition of these resources can be achieved by integration with other firms. In addition, networks evolve with the passage of time. Therefore, participants in networks should invest in relationships with other partners in the supply chain, and thus, they can acquire information and resources from other partners in the networks. 
An essential characteristic of the evolution of networks is that links are stronger and more stable with the passage of time. Inter-firm relationships in the network are developed by adaptation of the process and exchange of resources between partners in the supply chain process, and the relationships are closely related to the behavior of integration. The exchange includes the movement of information, goods and services between supply chain partners. Integration includes a personal bond as well as technological, logistical and managerial communication. Therefore, partners might gain similarity with each other as exchanges and confidence is gradually increased.

Adaptation of a supply chain process includes adjustments among goods, services, management systems and business processes to share resources more efficiently in a network. This adaptation is important two reasons. First, it enhances the bond between supply chain partners. If suppliers adjust their logistical processes to follow the requirements of specific customers, their dependence on the customers will be increased. Second, through these adjustments, the partners could keep constant and stable interrelationships as they aim for mutual long-term benefits.

Through integration, supply chain partners could structure various bonds with each other. Skjoett-Larsen (2000) categorized the bonds as follows: technical bonds concerned with adopting technology, social bonds such as inter-firm trust and knowledge, managerial bonds which result from managerial routine and procedural adjustments, and legal bonds as between firms. An accumulation of the effects concerned with these bonds could provide firms with better performance in conformity with creating continuous relationships between firms.

Networks that have a competitive edge and a stable position are useful to the firms that perform new investments and that look for new partners. A key factor of network strategy is not only to have a direct influence on some partners but also to have an indirect influence on the others. The activities of a firm in a supply chain network have an effect on suppliers of suppliers and on customers of customers as well as on suppliers and customers (Fawcett and Magnan, 2002). Therefore, the partners that conduct various activities in a supply chain can be connected by an inter-organizational network.

International freight forwarders should make various bonds with their partners in international logistical processes. When they execute these processes, they can achieve efficiencies by analyzing the current market environment and by strengthening communication with partners, and consequently, they can provide customers with high quality services. If they supply customers with high quality services at a low cost, they can enjoy a sustainable competitive advantage in the market, and as a result, the services become a competitive weapon. Therefore, if they enhance internal integration between departments and achieve external integration with business partners, they can 
provide customers with high quality, low cost services and, in turn, create benefits following efficient supply chain integration in international logistical processes.

\subsection{Supply chain integration}

Firms make an effort to collaborate in various activities: procurement, manufacturing, logistics and marketing. In addition, these activities are important in intra- and inter-firm aspects. In particular, a supply chain aspect that relates to inter-firm as well as inter-functional relationships is focused on the integration of an internal and external firm.

The concept of integration can be explained by three aspects: the first is inter-functional cooperative work in any aspect of the behavior of a firm, the second is regarded as the shared culture in the cultural context of a firm, and the third is collaborative relationships from the viewpoint of inter-firm relationships (Min et al., 2005). Integration in an inter-firm aspect could be performed as mutually-cooperative tasks, and inter-functional activities can be adjusted beyond the territory of a firm to achieve customer needs. Firms that want to carry out supply chain integration create a competitive advantage as a result of inter-firm information-sharing, joint decision-making and shared benefits, which results in enjoyment of higher performance through the satisfaction of customer needs. For these reasons, firms perform cooperative tasks with other partners in a supply chain (Simatupang and Sridharan, 2005).

Integration is very important for firms because it enhances their capability and performance (Min et al., 2005). Firms have recently concentrated their resources on core competence, and they also outsource functions that are not of core competence. In addition, the competition is not between firms but rather between supply chains. For this reason, supply chain partners should enhance their capabilities through intra-firm integration and they should also achieve high performance through inter-firm integration. Hence, integration could be performed on the basis of inter-firm business processes and relationships.

First, integration can be regarded as inter-firm business processes that perform cooperative tasks through integration between firms for a common objective that achieves reciprocal benefits (Stank et al., 2001/2002). Collaborative processes should include combined decision-making and problem-solving skills through an expansion of information-sharing among supply chain partners. Collaborative supply chains could be included in many firms and they could enjoy a competitive advantage in the market.

Second, integration can be explained as inter-firm relationships such as alliances or partnerships between supply chain partners. It includes working together for achieving integrated targets, shared information and resources and some level of risk sharing. It 
should be initially formed over the functional areas of a firm, and then, inter-functional integration could offer the basis of inter-firm integration because it is spread over supply chain partners. They also enjoy mutual dependence between functions through internal and external integration. They make connections between firms as well as between functions, and as a result, they acquire shared performance. Therefore, they agree to cooperate regarding human, financial and technological resources to improve supply chain processes.

This research on integration could be classified into two viewpoints in the supply chain: structural and behavioral. First, a structural viewpoint is grouped into vertical and horizontal integration (Barratt, 2004; Mason et al., 2007). Vertical integration includes integration between customers and suppliers as well as inter-functional integration, and horizontal integration includes external integration among some competitors (i.e., joint logistics) or collaborators (i.e., logistical service providers, information system providers) as well as internal integration in a firm. Second, a behavioral viewpoint can approach the active aspect of integration. It can be measured by the width and depth of integration (Min et al., 2005). Firms need to decide specific activities in which they should collaborate (width) because they cannot collaborate in all activities. After deciding the width, they should decide what they will collaborate among firms; that is, the depth of integration is a level of integration with regard to strategic, tactical and operative viewpoints because they cannot collaborate in all activities among firms. Some difficulties of effective management are due to the width and depth of integration, and increases with the number of partners in the supply chain. Therefore, firms must decide the width and depth of integration.

This research suggests a structural aspect to integration. Integration in a supply chain should be measured by both an inter-functional viewpoint and an inter-firm viewpoint. The viewpoints reflect a viewpoint of logistical service providers, such as international freight forwarders, and therefore, integration can be divided into internal and external integration.

\subsection{Development stages of integration in SCM}

Integration involves four development stages in SCM: independent operation, inter-functional integration, internal integration and external integration. The stages progress in a sequence from inter-functional to external integration (Narasimhan and Kim, 2001; Stevens, 1989).

The development stages can be explained as follows. First, independent operation of each activity in a firm means that they are operated separately in functional areas of a firm such as procurement, manufacturing, logistics, marketing, sales, service and 
distribution and each function is managed on a relatively independent basis. Second, inter-functional integration means that firms fulfill limited integration among similar functions, such as the procurement and management of raw material or loading/unloading and transportation. This stage stresses cost-efficiency rather than performance improvement. Third, internal integration is the real-time integration among all internal functional areas from the procurement of raw materials to manufacturing, logistics, marketing, sales and service. This stage provides visibility of the entire system, from procurement to distribution. Fourth, external integration includes some degree of supply chain integration by extending integration with business partners. Supply chain partners should structure the efficient relationships between partners through information-sharing and cooperative management in the inter-firm viewpoint (Narasimhan and Kim, 2001).

According to prior research, the development stages of integration in SCM are required to achieve inter-firm integration and intra-firm integration. Thus, integration is performed from inter-functional areas to external areas. The development stages should be developed by recognition of SCM, inter-functional integration and integration between firms in a normal sequence. However, the development stages are regarded as a strategic choice of a firm at a given time in this research. Supply chain partners need to ascertain where they are in the stages. Therefore, integration, in this research, is explained with internal and external aspects in a supply chain, and the development is suggested as having four stages: independent operation, internal integration, external integration and supply chain integration.

\section{Figure 1.}

Development stages of integration in SCM

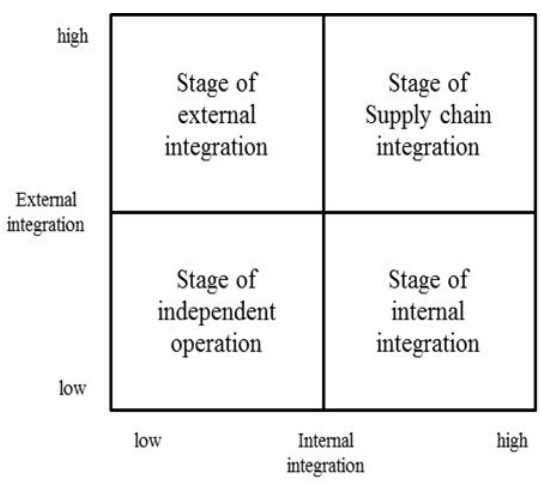

As shown in $<$ Figure $1>$, the stage of independent operation represents a lack of recognition of SCM. In addition, firms maintain efficiency of internal processes through 
a high level of internal integration in response to a stable external environment. Conversely, firms secure opportunities through a high level of external integration if the environment is highly uncertain, and finally, they choose supply chain integration if they think it is important to improve the effectiveness of inter-firm processes and the efficiency of internal processes by improving the capability of information systems.

It is important to test the level of integration of firms in this research because one of the objectives of this research is to estimate where firms are in the stages. If firms focus on internal integration, their supply chain strategy improves internal efficiency; on the other hand, if the strategy puts stress on network efficiency, firms focus on external integration. In addition, if firms focus on both of these aspects, supply chain effectiveness is maximized. For these reasons, this research suggests that development stages of integration are not explained as the flow of the stages but as the strategic choice concerned with their current decision-making.

\section{RESEARCH HYPOTHESIS AND METHODOLOGY}

\subsection{Development stages of integration and performance}

Integration can involve three dimensions in a logistical process: 1) two or more logistical activities such as transportation, loading, unloading and storage, 2) logistical activities between departments such as the department of logistics and the department of marketing, and 3) logistical activities between supply chain partners (Stevens, 1989). Firms should integrate the activities to achieve their goals.

Supply chain integration begins with an internal aspect of a firm, is developed into the relationships between partners, and finally, creates performance such as service effectiveness and cost efficiency. In addition, integration is important for achieving external integration to connect suppliers and customers as well as for achieving internal integration in a firm for efficient SCM. For this reason, the development stages of integration can be explained to comprise two elements: one is to efficiently structure internal systems through internal integration, and the other is to accomplish collaboration between supply chain partners through external integration, which connects inter-firm systems. Firms, through integration, attain cost advantages such as cost savings following the efficient use of resources, lower waste by reducing overlaps of resources, proper replacement of resources and improved efficiency of processes. Therefore, firms enjoy higher cost performance if they are at a higher development stage of integration.

Integration should include decision-making between firms and joint responsibility as the result of the process of decision-making between supply chain partners. 
Managers should make an effort to form a collaborative spirit between supply chain partners and departments by making a cooperative effort in common activities, and they should achieve joint goals through interaction. Even if they give up the goals of a department or a firm, they should achieve supply chain goals by adjusting inefficient processes and thus adding value to the supply chain process (Stank et al., 2001/2002). In addition, firms that participate in the process provide customers with high quality services because of attaining joint goals, responding to customer needs and performing cooperative operation by sharing information with business partners. These firms should thus enjoy differentiation compared with competitors in the market. Therefore, international freight forwarders could enjoy cost performance and service performance if they achieve a high stage of integration.

H. 1 There is a gap in cost performance among development stages of integration.

H. 2 There is a gap in service performance among development stages of integration.

\subsection{Measurement of variables}

Various measurement factors have been developed by prior research for testing the hypotheses of this research. Definitions and scales of variables are as follows. First, supply chain integration can be divided into internal and external integration (Narasimhan and Kim, 2001). Internal integration is explained as collaboration and interaction between departments that appear in human and physical management and the internal flow of information in a firm. External integration is regarded as operational cooperation that concerns the logistics between business partners (Stock et al., 2000). Second, performance is grouped into two classes: cost performance and service performance (Stank et al., 2001/2002). Cost performance is the degree of cost saving in logistical processes and reflects financial aspects. Service performance is explained as the ability to correspond to a requirement of customers in logistical processes and it reflects non-financial aspects. All items are measured for perceptions on a 7-point Likert scale.

\subsection{Sampling and methods of data collection}

The population is international freight forwarders in the Republic of Korea and the sample frame is the membership list of the Korean International Freight Forwarders Association. The forwarders must become a member of the association if they want to work as an international freight forwarder. Hence, the list becomes the sample frame. Approximately 800 firms were included in the sample frame, and this research 
investigated the entire population.

A staff member from the management department or the sales department of the firms responded to the questionnaire. Because of the facts that they have had vast work experience, have worked in the field and have understood the work, they exactly reflected the business practice of the forwarders. Questionnaires were collected by mail, email, telephone, facsimile and personal visits from April 2009 to August 2009. After excluding incomplete questionnaires, an analysis was performed on a total of 275 firms.

\subsection{Methodology for analysis}

This research uses several analytic methods. First, the reliability of each variable is tested by Cronbach's alpha coefficient and unidimensional characteristics for each factor are verified by principal component analysis through a factor analysis. Reliability can be explained as the possibility of obtaining the same results when measurement is repeated. The reliability of this research is determined with Cronbach's alpha coefficients and is considered good if the coefficient is greater than 0.6 proposed by Nunnally (1978). Validity means that measurement reflects concepts or features of variables. A factor analysis is used to delete scale items that hinder the validity of the variables. It is tested by factor analysis. If factor loading coefficients are over 0.6 , it is considered good.

Second, cluster analysis divides respondents into clusters for examining the development stages of integration, and then, gaps in performance between the clusters are tested by an analysis of variance and a post hoc analysis (Duncan test). The analysis methods used are as follows. First, cluster analysis is one of the methods used to classify strategic groups (Thomas and Venkatraman, 1988). Firstly, this method makes concepts in various dimensions, and secondly, the groups are divided into four clusters to use ad hoc criteria found in prior research. This process classifies groups into two stages: the first stage is to make dimensions for classification through a factor analysis of the data, and the second stage is to make groups through the cluster analysis to use the dimensions. A cluster analysis is applied to Word's method of the methods of hierarchical classification to determine a number of clusters using the coefficients and a Dendrogram. Second, the data is tested by an analysis of variance, which is first used for verifying gaps in integration between groups. However, a limitation of an analysis of variance is that the result of the analysis cannot determine how they are classified as different groups. The result of the analysis can only verify that the average between groups is different if they are different groups. Therefore, this research analyzes the heterogeneity between the groups with the Duncan test as a post hoc analysis. The analyses are performed by SPSS 18.0. 


\section{RESULTS OF EMPIRICAL TESTS}

\subsection{General characteristics of the responding firms}

The annual turnover of the responding firms is as follows in $<$ Table $1>$.

Table 1.

Annual turnover of the sample firms (unit: U\$100,000)

\begin{tabular}{|c|c|c|c|c|c|}
\hline Division & Less than 5 & $6-50$ & More than 50 & No answer & Total \\
\hline Frequency & 82 & 88 & 33 & 72 & 275 \\
\hline Ratio (\%) & 29.8 & 32.0 & 12.0 & 26.2 & 100 \\
\hline
\end{tabular}

Annual turnover of 82 firms $(29.8 \%)$ was less than U\$ 0.5 million and of 33 firms $(12.0 \%)$ was over U\$ 5 million in 2008. In addition, there were 72 non-answering firms $(26.2 \%)$, which were assumed to do not want to have their annual turnover published because they treat it as confidential.

\subsection{Reliability and validity}

The results of the factor analysis and Cronbach's alpha coefficients are as follows in $<$ Table $2>$.

Table 2.

The results of factor analysis and reliability test

\begin{tabular}{|c|c|c|c|c|}
\hline Items & $\begin{array}{l}\text { Factor } \\
\text { loading }\end{array}$ & Eignvalue & $\begin{array}{c}\text { Variance } \\
(\%)\end{array}$ & $\begin{array}{c}\text { Cronbach's } \\
\text { alpha }\end{array}$ \\
\hline $\begin{array}{l}\text { INT 1: vigorous information exchange between departments } \\
\text { INT 2: vigorous information control between departments } \\
\text { INT 3: communication concerning information-sharing } \\
\text { INT 4: meetings for information exchange } \\
\text { INT 5: formal meetings between departments }\end{array}$ & $\begin{array}{l}0.717 \\
0.708 \\
0.768 \\
0.772 \\
0.712 \\
\end{array}$ & 3.775 & 19.869 & 0.918 \\
\hline $\begin{array}{l}\text { INT 6: coordination on logistical processes with partners } \\
\text { INT 7: cooperation for maintaining logistics flow } \\
\text { INT 8: information-sharing on logistics } \\
\text { INT 9: harmonious information exchange with partners }\end{array}$ & $\begin{array}{l}0.626 \\
0.774 \\
0.843 \\
0.772\end{array}$ & 3.405 & 17.921 & 0.885 \\
\hline $\begin{array}{l}\text { COS 1: contact cost saving with business partners } \\
\operatorname{COS} 2 \text { : cost savings to equipment and human resources } \\
\operatorname{COS} 3 \text { : cost savings in transportation and warehouse costs } \\
\operatorname{COS} 4 \text { : administrative cost savings }\end{array}$ & $\begin{array}{l}0.793 \\
0.813 \\
0.767 \\
0.730\end{array}$ & 3.138 & 16.515 & 0.895 \\
\hline $\begin{array}{l}\text { SER 1: increasing flexibility of operations } \\
\text { SER 2: the ability to agree with a changed customers needs } \\
\text { SER 3: sustainable information-sharing to logistical services } \\
\text { SER 4: to supply customers with additional services } \\
\text { SER 5: collaborative settlement of problems }\end{array}$ & $\begin{array}{l}0.816 \\
0.868 \\
0.831 \\
0.823 \\
0.780\end{array}$ & 4.012 & 21.115 & 0.921 \\
\hline
\end{tabular}

According to the results, there are four variables: internal integration, external integration, cost performance, and service performance. The factor loading coefficients 
and Cronbach's alpha coefficients of each variable show over 0.6, and consequently, validity and reliability are considered good.

\subsection{Hypothesis testing}

This research tests gaps in performance achieved by firms among development stages of integration. Depending on the development stages, integration is divided into four stages: independent operations, internal integration, external integration and supply chain integration. To test the stages empirically, this research uses the method of classifying strategic groups, which is usually used in strategic management research. In addition, gaps in performance between the groups are be tested by cluster analysis, analysis of variance and post hoc analysis. As shown in $<$ Table 3>, four groups are in both the internal and external integration stages.

Table 3.

The results of the analysis

\begin{tabular}{|c|c|c|c|c|c|}
\hline Criteria & $\begin{array}{c}\text { Cluster 4 } \\
(\mathrm{n}=94)\end{array}$ & $\begin{array}{c}\text { Cluster 3 } \\
(\mathrm{n}=94)\end{array}$ & $\begin{array}{c}\text { Cluster } 1 \\
(\mathrm{n}=42)\end{array}$ & $\begin{array}{c}\text { Cluster 2 } \\
(\mathrm{n}=45)\end{array}$ & ANOVA \\
\hline $\begin{array}{c}\text { Internal } \\
\text { integration }\end{array}$ & 3.2412 & 4.6143 & & & 146.259 \\
& & & 6.2000 & 6.1875 & $(\mathrm{p}<0.000)$ \\
\hline $\begin{array}{c}\text { External } \\
\text { integration }\end{array}$ & 3.4824 & 4.1000 & & 116.504 \\
& & 4.8762 & & 6.0375 & $(\mathrm{p}<0.000)$ \\
\hline
\end{tabular}

As shown in $<$ Table 3>, the clusters are divided as follows. First, cluster 4 shows the lowest coefficients in internal and external integration. For this reason, cluster 4 can be regarded as a stage of independent operations. Second, cluster 3 shows that internal integration is higher than cluster 4 but lower than cluster 1 and 2 and external integration is higher than cluster 1 and 4 but lower than 2 . Therefore, cluster 3 is regarded as a stage of external integration. Third, cluster 1 represents the highest internal integration of all clusters and external integration is higher than cluster 4 but lower than cluster 2 and 3. Hence, cluster 1 is considered a stage of internal integration. Fourth, cluster 2 shows a coefficient of internal integration similar to cluster 1 , and the coefficient is higher than cluster 3 and 4 . The external integration is shown to be higher than the others. Therefore, cluster 2 can be regarded as a stage of supply chain integration.

The results explain the development stages of integration for each cluster. Cluster 4, which has 94 firms at a stage of independent operation, is made up of many small international freight forwarders that may not have a correct understanding of supply 
chain integration. Cluster 3, representing the stage of external integration, has 94 firms that achieve a high stage of external integration because they perform many inter-firm activities. Cluster 1, representing the stage of internal integration, has 42 firms, and they achieve high internal integration through communication and cooperation among their functional areas. Finally, Cluster 2 has 45 firms, and they are at the highest stage of development: supply chain integration. Thus, they have a great deal of collaborative processes from both internal and external aspects.

The classified clusters for testing hypotheses are analyzed by an analysis of variance to ascertain whether there are gaps in cost and service performance as suggested in this research, and then, a post hoc analysis is used to analyze the substantial gaps in performance between clusters. The results of the analysis of variance and post hoc analysis through the Duncan test on gaps in performance between clusters are provided in $\langle$ Table $4>$.

\section{Table 4.}

The results of ANOVA and post hoc analysis (Duncan test)

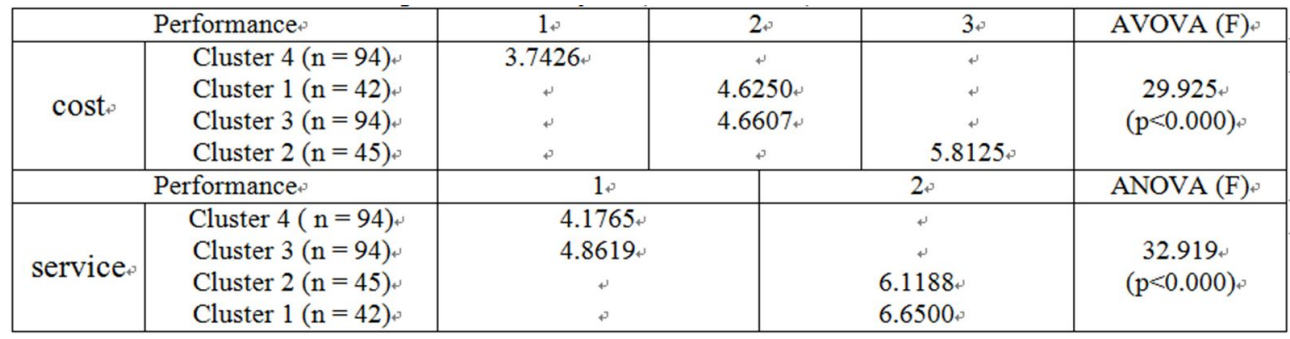

As shown in <Table 4>, cost performance reveals a meaningful gap between clusters. Cluster 2, as the stage of supply chain integration, shows the highest performance (H.1 supported). As a result of the post hoc analysis on cost performance between the clusters, there are three different groups: cluster 4, cluster 1 and 3 , and cluster 2. The result means that better cost performance can be achieved in the stages of internal and external integration as well as in the stage of supply chain integration and that a stage of independent operation shows the lowest cost performance. Therefore, if firms want to enjoy a highest cost performance, they should attain a stage of supply chain integration. Moreover, firms in the stages of internal and external integration can enjoy cost performance, but the cost performance is lower than the performance in the stage of supply chain integration.

There are gaps among the clusters in service performance (H. 2 supported). As the result of a post hoc analysis, as shown in $\langle$ Table $3>$, the coefficients of clusters 1 and 2 are much higher than the coefficients of cluster 3 and 4 in internal integration. Consequently, the firms are regarded as achieving higher service performance if they 
attain internal integration rather than external integration (Table 4). Therefore, international freight forwarders that achieve high internal integration can provide high quality service for their customers.

As shown in <Table $4>$, firms that are in a stage of independent operations can enjoy higher performance if they proceed to a stage of internal integration. They can increase from 3.7426 to 4.6250 in cost performance and from 4.1765 to 6.6500 in service performance. In addition, firms that are in a stage of independent operation can enjoy superior performance if they proceed to external integration. They can increase cost performance from 3.7426 to 4.6607 and service performance from 4.1765 to 4.8619. Internal and external integration can enjoy the highest performance if they proceed to a stage of supply chain integration by stressing external integration as well as internal integration. Firms that are in a stage of internal integration can increase cost performance from 4.6250 to 5.8125 and increase service performance from 6.6500 to 6.1188. Similarly, firms that are in a stage of external integration can increase cost performance from 4.6607 to 5.8125 and service performance from 4.8619 to 6.1188 . The results support the focused strategy of Porter (1980) because firms which are in a stage of independent operations can choose either a stage of internal integration or a stage of external integration. Internal integration is to keep external integration and to increase internal integration, whereas external integration is to keep internal integration and to increase external integration. Firms can achieve the highest performance if they achieve supply chain integration. <Figure $2>$ shows the flow of development stages of integration in SCM.

\section{Figure 2.}

The flow of development stages of integration in SCM

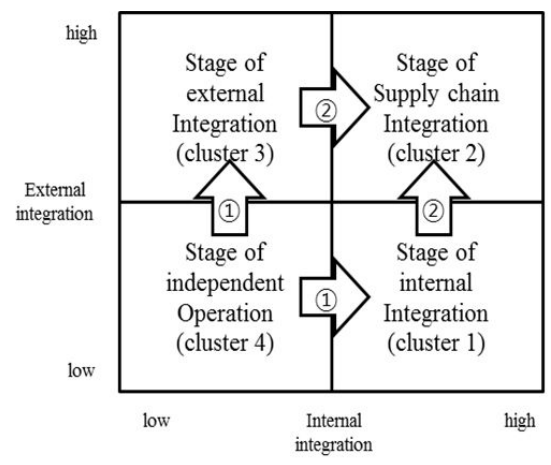




\section{CONCLUSION}

International freight forwarders are important for their management of logistical processes on behalf of shippers in the area of international logistical processes. They perform an important role in providing efficient logistical services for customers and carrying out seamless logistical flow in the interface of international logistics. It is very important to investigate a level of integration in inter-firm processes and internal processes in a firm because integration is one of the core factors in structuring an efficient supply chain process. In addition, this research on gaps in performance among the development stages of integration in SCM can provide a background to secure superior performance following SCM by empirically testing the relationships between their strategy and performance.

The theoretical relationships for an analysis are examined in the literature review, and conceptual and operational definitions are made in the review. Questionnaires were sent to international freight forwarders, and an analysis of 275 firms was performed. Analyses were performed by two methods. The first comprised analyses of reliability and validity using Cronbach's alpha and factor analysis, and the second comprised analyzing gaps in performance among development stages of integration in SCM using cluster analysis, analysis of variance and post hoc analysis (Duncan test). The discussion below is organized as follows: theoretical implications, managerial implications and limitations of this research.

Theoretical implications of the results are as follows. First, the development stages of integration reflect a strategic choice of each firm. Prior research explains the stages as the flow of the strategy from internal to external integration (Narasimhan and Kim, 2001; Stevens, 1989). However, this research treats the stages as a strategic choice of a firm following the contingencies that they face. Their present position in the development stages could be reviewed, and consequently, firms could perform a strategic choice for improving performance. Therefore, the development stages of integration could be applied to various research projects in a strategic viewpoint. Second, the development stages of integration are explained as independent operations, internal integration, external integration and supply chain integration in this research. The stages can be explained as the focused strategy by Porter (1980). In other words, internal integration means that firms maximize performance by increasing internal integration and maintaining external integration; conversely, external integration means that firms maximize performance through increasing external integration and maintaining internal integration. Furthermore, they achieve the highest performance through supply chain integration. Therefore, this research examines the development stages of integration through a strategic viewpoint and provides future researchers with various 
viewpoints concerned with strategic research.

The managerial implications of this research are as follows. First, international freight forwarders should make efficient international logistical processes as logistics experts by structuring network systems and securing superior internal resources. The logistical processes are the basis of their core competence to support customers' global SCM. Second, the forwarders should attain internal efficiency through collaborative inter-departmental relationships and encourage cooperative networking through information-sharing with business partners. As a result of integration, firms can remove overlaps and inefficiencies of logistical processes in conformity with the use of information technology such as the Internet. In addition, they can provide high quality logistical services for customers because they can respond to customer needs with business partners in the market. Third, the forwarders perform simple tasks in international logistical processes such as the consolidation of goods. As a result, they suffer low profits. For this reason, they should structure systems that execute global SCM on behalf of customers because their customers perform global SCM. In addition, they should enhance the capability to manage customers' logistical processes as supply chain managers in entire processes and design processes for global SCM. The first step for enhancing the capability is to integrate internal and external processes because the results of this research demonstrate that cluster 2, which represents the stage of supply chain integration, enjoyed the highest cost performance and high service performance.

There are two limitations of the present research. First, this study does not use variables that reflect the characteristics of international freight forwarders as logistical service providers because this kind of research is theoretical. Therefore, the variables could be developed by continuous research of the industry. Second, this research tests only the relationships between integration and performance. Environmental and internal factors that influence integration are overlooked in this research. The application of information technology has been recently recognized as one of the important factors in SCM (Frohlich and Westbrook, 2001). In particular, firms could have a different level of SCM capability following IT infrastructure improvements. These research limitations provide future research directions: the development of variables concerned with logistical service providers and an investigation into influencing variables on integration. 


\section{REFERENCES}

Bae, H. 2011. The Relationships between Environment, Integration and Performance in Supply Chain Contexts. The Asian Journal of Shipping and Logistics. 27(1): 61-90.

Bae, H. Y.K. Lee and W.Y. Lee. 2012. The Effect of Innovation and Market

Orientation on Customer Service for Customs Clearance Firms in the International

Logistics Processes. Journal of International Logistics and Trade. 10(1): 109-133.

Bagchi, P.K., B.C. Ha, T. Skjoett-Larsen and L.B. Soerensen. 2005. Supply Chain Integration: a European Survey. The International Journal of Logistics Management. 16(2): 275-294.

Barratt, M. 2004. Understanding the Meaning of Integration in the Supply Chain.

Supply Chain Management: An International Journal. 9(1): 30-42.

Elg, U. and U. Johansson. 1996. Networking when National Boundaries Dissolve: The Swedish Food Sector. European Journal of Marketing. 30(2): 61-74.

Ellinger, A.E. 2000. Improving Marketing/Logistics Cross-functional Integration in the Supply Chain. Industrial Marketing Management. 29: 85-96.

Fawcett, S.E. and G.M. Magnan. 2002. The Rhetoric and Reality of Supply Chain Integration. International Journal of Physical Distribution and Logistics Management. 32(5): 339-361.

Frohlich, M.T. and R. Westbrook. 2001. Arcs of Integration: An International Study of Supply Chain Strategies. Journal of Operations Management. 19: 185-200.

Gimenez, C. 2006. Logistics Integration Processes in the Food Industry. International Journal of Physical Distribution and Logistics Management. 36(3): 231-249.

Gunasekaran, A., C. Patel and R.E. McGaughey. 2004. A Framework for Supply Chain Performance Measurement. International Journal of Production Economics. 87: 333-347.

Holmberg, S.A. 2000. System Perspective on Supply Chain Measurements. International Journal of Physical Distribution and Logistics Management. 30(10): 847-868.

Lau, A.K.W., R.C.M. Yan, E.P.Y. Tang and H.Y. Sun. 2010. Factors Influencing the Relationship between Product Modularity and Supply Chain Integration. International Journal of Operations and Production and Management. 30(9): 951-977.

Mason, R., C. Lalwani and R. Boughton. 2007. Combing Vertical and Horizontal Integration for Transport Optimisation. Supply Chain Management: An International Journal. 12(3): 187-199.

Matopoulos, A., M. Vlachopoulou, V. Manthou and B. Manos. 2007. A Conceptual Framework for Supply Chain Integration: Empirical Evidence from the Agri-food 
Industry. Supply Chain Management: An International Journal. 12(3): 177-186.

Min, S., A.S. Roath, P.J. Daugherty, S.E. Genchev, H. Chen, D. Arndt and R.G. Richey. 2005. Supply Chain Integration: What's Happening? The International Journal of Logistics Management. 16(2): 237-256.

Mollenkopf, D., A. Gibson and L. Ozanne. 2000. The Integration of Marketing and Logistics Functions: An Empirical Examination of New Zealand Firms. Journal of Business Logistics. 21(2): 89-112.

Narasimhan, R. and S.W. Kim. 2001. Information System Utilization Strategy for Supply Chain Integration. Journal of Business Logistics. 22(2): 51-75.

Nunnally, J. 1978. Psychometric Theory, McGrow-Hill.

O'Donnell, A.A., L.M. Rinehart and M.V. Wells. 1992. Rethinking Concept Foundations in Logistics Management. Journal of Business Logistics. 13(2): 233-267.

Porter, M.E. 1980. Competitive Strategy. New York, Free Press.

Sheu, C.H., R. Yen and B. Chae. 2006. Determinants of Supplier-Retailer Integration: Evidence from an International Study. International Journal of Operation and Production Management. 30(10): 847-868.

Simatupang, T.M. and R. Sridharan. 2005. The Integration Index: A Measure for

Supply Chain Integration. International Journal of Physical Distribution and Logistics Management. 35(1): 44-62.

Skjoett-Larson, T. 2000. Third Party Logistics-from an Interorganizational Point of View. International Journal of Physical Distribution and Logistics Management. 30(2): 112-127.

So, S.C.K. and H. Sun. 2010. Supplier Integration Strategy for Lean Manufacturing Adoption in Electronic-enable Supply Chains. Supply Chain Management: An International Journal. 15(6): 1-30.

Stank, T.P., S.B. Keller and D.J. Closs. 2001/2002. Performance Benefits of Supply Chain Logistical Integration. Transportation Journal. 41(2/3): 32-46.

Stevens, G.C. 1989. Integrating the Supply Chain. International Journal of Physical Distribution and Logistics Management. 19(8): 3-8.

Stock, G.N. N.P. Greis and J.D. Kasada. 2000. Enterprise Logistics and Supply Chain Structure: the Role of Fit. Journal of Operations Management. 18: 531-547.

Thomas, H. and N. Venkatraman. 1988. Research on Strategic Groups: Progress and Prognosis. Journal of Management Studies. 25(6): 537-555.

Venkatraman, N. 1989. The Concept of Fit in Strategy Research: toward Verbal and Statistical Correspondence. The Academy of Management Review. 14(3): 423-444.

Wiengarten, F., P. Humphreys, G. Cao, B. Fynes and A. Mckittrick. 2010. Collaborative Supply Chain Practices and Performance: Exploring the Key Role of 
Information Quality. Supply Chain Management: An International Journal. 15(6): 1-27.

Williams, L.R., A. Nibbs, D. Irby and T. Inley. 1997. Logistics Integration: the Effect of Information Technology, Team Composition and Corporate Competitive Positioning. Journal of Business Logistics. 18(2): 31-41.

Williamson, O.E. 1991. Comparative Economic Organisation: the Analysis of Discrete Structural Alternatives. Administrative Science Quarterly. 36: 269-296.

Williamson, O.E. 1996. Economic Organisation: the Case for Cander. Academy of Management Review. 21(1): 48-57.

$\mathrm{Wu}$, Y.C.J. 2006. Assessment of Technological Innovations in Patenting 3rdPartyLogisticsProviders.Journal of Enterprise Information Management. 19(5): 504-524. 